Original Research Article

\title{
Student's perceptions and feedback about teaching-learning pharmacology in Nepalgunj medical college of Chisapani, Nepal
}

\author{
Dabal B. Dhami*, R.S. Rathor, V. K. Bhargava, Ganesh Neupane, Ritesh Singh, Ankita Singh
}

Department of Pharmacology, Nepalgunj Medical College, Chis apani, Banke, Nepal

Received: 12 October 2017

Revised: 29 October 2017

Accepted: 03 November 2017

*Correspondence to:

Dr. Dabal B. Dhami,

Email: drddhami@gmail.com

Copyright: (C) the author(s), publisher and licensee Medip Academy. This is an openaccess article distributed under the terms of the Creative Commons Attribution NonCommercial License, which permits unrestricted noncommercial use, distribution, and reproduction in any medium, provided the original work is properly cited.

\begin{abstract}
Background: Pharmacology, being both basic and applied science, forms the backbone of rational therapeutics in medical field. Understanding of current perceptions and opinions of medical students is important for the betterment of teaching-learning methodologies in pharmacology subject. This study done with the objective to determine the perception and feedback of teaching learning pharmacology.

Methods: Descriptive cross sectional questionnaire based study was conducted in Nepalgunj Medical College Chisapani, Banke Nepal, among second year MBBS students in September 2017. A questionnaire distributed in class and then collected. Data was analysed using the Statistical Package for Social Sciences (SPSS).

Results: Total 119 students, 78 male and 41 females participated in this study. The percentage average of agreed responses for 15 questions $(58.92 \pm 19.53)$ was significant $(\mathrm{p}<0.05)$ when compared with the percentage average of the disagreed (5.42 \pm 5.17). Seventy three $(61.3 \%)$ students agreed that pharmacology is a favourite subject but the preferences for pharmacology as a subject in postgraduation was low (18.5\%). High proportion of students wanted the faculty members to make more use of Audio-Visual aids 93.3\%, case based learning 96.6\%, more clinical pharmacology, 97.5\%, group discussions, $88.2 \%$, integration to clinical sciences $92.4 \%$ and $82.4 \%$ prefer MCQs to be introduced in the curriculum for effective learning.

Conclusions: Introduction of integrated teaching, MCQs, case based, and group based discussion with clinical pharmacology and audio-visual aids was favoured by majority of the students. Regular reviewing perception and feedback of the students help teachers to plan the curriculum and improve the teaching methodologies.
\end{abstract}

Keywor ds: Feedback, Pharmacology, Perception, Student, Teaching-learning

\section{INTRODUCTION}

Pharmacology is a crucial subject for medical students who are going to be future medical practitioners, specialists and super specialists in various discipline. It is therefore important that medical students appreciate pharmacological principles and are able to correlate and apply them in the practice of medicine. ${ }^{1}$ Understanding current scenario of medical undergraduates regarding teaching as well as learning pharmacology and understanding its vital role in academics, clinics and research may greatly help in improving the teaching of this discipline. ${ }^{2}$ Student feedback has been considered to be an effective methodology for modification of undergraduate curriculum and making pharmacology more interesting and practicable. ${ }^{3}$ It is generally agreed that reviewing the teaching program at regular intervals and modifications in the methodologies of imparting basic knowledge about drugs and drug therapies is a must. ${ }^{4}$ Students' feedback would probably reveal whether the so called reforms are acceptable to them and their opinion for the betterment of teaching learning pharmacology subject. ${ }^{5}$ 
Several studies on students' perceptions regarding learning of pharmacology documented students' improvements in performance through improved teaching and learning processes. ${ }^{6}$ Understanding current perceptions held by future medical practitioners regarding pharmacology and its role in both research and clinical practice may be helpful for improving teaching on this subject and introducing appropriate changes into the curricula as and where necessary. ${ }^{7}$ In order to assess the strength of the pharmacology curriculum and students' learning experience in this setting, collection of the students feedback was done so that necessary reforms can be implemented for the betterment of teaching-learning pharmacology. ${ }^{2}$ In Nepal, limited study had been done on the medical student's perception and feedback on teaching learning of pharmacology and therapeutics however pharmacology is taught in first two years of MBBS course. So, this study was conducted to determine the perception and feedback of teaching learning pharmacology in second year MBBS student of Nepalgunj Medical College, Chis apani, Nepal.

\section{METHODS}

The descriptive cross sectional questionnaire based study was conducted at Nepalgunj Medical College. Chisapani, Banke Nepal, among second year MBBS students of Batch 2016 in September 2017. Questionnaire was designed based on the literature review in this field. ${ }^{4,5,8} \mathrm{With}$ modification including demographic data of students and distributed to students after short briefing about the aims and objectives of this study and all students present in the class at the time of distribution were included in the study after informed consent. Thirty minute time was given for answering the questionnaire, and then the questionnaires were collected.

\section{Inclusion criteria}

- All male and female students of second year MBBS who present in the class at the time of distribution of questionnaire.

- Students who completed the questionnaire after informed consent.

\section{Exclusion criteria}

- Participant who do not completed the questionnaire.

- Students who did not give informed consent.

Total 119 data were collected and analysed using the Statistical Package for Social Sciences (SPSS) and $p$ value $<0.05$ was considered as statistically significant.

\section{RESULTS}

\section{Demographic variables of the participants}

Total 119 students participated in this study. Among them $65.5 \%$ were male and $34.5 \%$ female. The mean age \pm SD of the student was $20.4 \pm 1.05$. Majority of them were Nepalese $64.7 \%$ followed by Indian $35.3 \%$ (Table 1).

Table 1: Demographic variables of the participants $(\mathrm{n}=119)$.

\begin{tabular}{|llll|}
\hline & Minimum & Maximum & Mean \pm SD \\
\hline Age & 18 & 23 & $20.4 \pm 1.05$ \\
\hline Sex & Frequency & Percentages \\
\hline Male & 78 & 65.5 \\
\hline Female & 41 & 34.5 \\
\hline Nationality & & \\
\hline Nepalese & 77 & 64.7 \\
\hline Indian & 42 & 35.3 \\
\hline
\end{tabular}

\section{Perceptions and opinion towards teaching and learning pharmacology by students}

Seventy three $(61.3 \%)$ agreed that pharmacology is their favourite subject and $42(35.3 \%)$ were neutral, however, only students $22(18.5 \%)$ considered pharmacology for post-graduation whereas $72(60.5 \%)$ were neutral. The majority of the students $101 \quad(84.9 \%)$ agreed that pharmacology has created a knowledge base that will help them with the rational choice of drugs during future practice. Sixty-eight students $(57.1 \%)$ mentioned that pharmacology lectures are interesting and stimulating, Highest $92.4 \%$ students agreed that pharmacology is more closely integrated with the clinical sciences, and real cases from hospitals should be used during stimulated learning problems and $61.3 \%$ agreed pharmacology helps in developing their skills in problem-solving and logicalreasoning. About $50 \%$ were neutral on the topic that the teaching of pharmacology should focus strongly on the health problems of Nepal, whereas $42 \%$ agreed and $8.4 \%$ disagreed. Regarding the need for practical sessions on rationality of prescription and evaluation of drug advertisements and modules of pharmacology during their clinical years agreed by 63.95 and $65.5 \%$ respectively. Nearly $50 \%$ agreed that the assessment system is fair whereas $42.9 \%$ were neutral and more than half, $52.9 \%$ agreed with transparency of assessment. Majority of student agreed that MCQs should be included in the assessment $82.4 \%$ and $71.4 \%$ agreed that practical sessions as well as the objectively structured practical examination (OSPE) and problem stimulated learning (PSL) more than didactic lectures and 64 (53.8\%) agreed that pharmacology education had given them capacity for self-directed learning Less than half 49 (41.2\%) agreed with that the assessment focuses on the ability to acquire facts rather than the development of problem solving skills whereas more than half $57.1 \%$ maintained neutrality (Table 2).

\section{Ideal teaching learning methods in pharmacology at NGMC}

Majority of student $79 \%$ agreed combination of LCD projector and blackboard followed by LCD projector 
$(12.6 \%)$ as ideal teaching-learning media for pharmacology. Group discussions favored by $45.4 \%$, followed by tutorials, $16.5 \%$ and demonstration, $13.4 \%$. The most difficult system to understand was antimicrobials $(52.1 \%)$ followed by central and autonomic nervous system, (13.4\%) each (Table 3).

Table 2: Perceptions and opinion towards pharmacology teaching and learning by students (n=119).

\begin{tabular}{|c|c|c|c|}
\hline Statements & Disagree & Neutral & Agree \\
\hline Pharmacology is my favorite subject in the basic sciences. & $4(3.4 \%)$ & $42(35.3 \%)$ & $73(61.3 \%)$ \\
\hline $\begin{array}{l}\text { The subject has created the knowledge base which will help me in choosing } \\
\text { drugs rationally in my future practice. }\end{array}$ & $1(0.8 \%)$ & $17(14.3 \%)$ & $101(84.9 \%)$ \\
\hline I find pharmacology lecturers interesting and stimulating & $4(3.4 \%)$ & $47(39.9 \%)$ & $68(57.1 \%)$ \\
\hline $\begin{array}{l}\text { I would like Pharmacology to be more closely integrated with the clinical } \\
\text { sciences and would like real cases in hospital to be used during problems } \\
\text { stimulated learning (PSL) }\end{array}$ & $2(1.6 \%)$ & $7(6 \%)$ & $110(92.4 \%)$ \\
\hline $\begin{array}{l}\text { The subject has helped me to develop my problem-solving and logical- } \\
\text { reasoning skills. }\end{array}$ & $7(5.9 \%)$ & $39(32.8 \%)$ & $73(61.3 \%)$ \\
\hline $\begin{array}{l}\text { I would like the subject to be focus more strongly on the health problems of } \\
\text { Nepal. }\end{array}$ & $10(8.4 \%)$ & $59(49.6 \%)$ & $50(42.0 \%)$ \\
\hline $\begin{array}{l}\text { I would like practical session on rationality of prescription and evaluation of } \\
\text { drug advertisements }\end{array}$ & $9(7.6 \%)$ & $34(28.6 \%)$ & $76(63.9 \%)$ \\
\hline $\begin{array}{l}\text { I would like to welcome modules on Pharmacology and therapeutics during } \\
\text { the clinical years of my training. }\end{array}$ & $1(0.8 \%)$ & $40(33.6 \%)$ & $78(65.5 \%)$ \\
\hline The assessment systemin Pharmacology is fair. & $9(7.6 \%)$ & $51(42.9 \%)$ & $59(49.6 \%)$ \\
\hline The as sessment process is transparent. & $10(8.4 \%)$ & $63(52.9 \%)$ & $46(38.7 \%)$ \\
\hline I would like MCQs to be included in the as sessment. & $3(2.5 \%)$ & $18(15.1 \%)$ & $98(82.4 \%)$ \\
\hline $\begin{array}{l}\text { The assessment concentrates on ability to acquire facts rather than on the } \\
\text { development of problem-solving skills. }\end{array}$ & $2(1.7 \%)$ & $68(57.1 \%)$ & $49(41.2 \%)$ \\
\hline $\begin{array}{l}\text { The Pharmacology teaching has inculcated in me a capacity for self-directed } \\
\text { learning. }\end{array}$ & $8(6.7 \%)$ & $47(39.5 \%)$ & $64(53.8 \%)$ \\
\hline I will consider Pharmacology as one of my subject for post-graduation & $25(21 \%)$ & $72(60.5 \%)$ & $22(18.5 \%)$ \\
\hline $\begin{array}{l}\text { There should be more emphasis on objective structured practical examination } \\
\text { (OSPE) and PSL, rather than didactic lectures }\end{array}$ & $2(1.6 \%)$ & $32(27 \%)$ & $85(71.4 \%)$ \\
\hline
\end{tabular}

Table 3: Teaching-learning methods in pharmacology at NGMC $(n=119)$.

\begin{tabular}{|lcl|}
\hline $\begin{array}{l}\text { The ideal Teaching learning } \\
\text { method for learning }\end{array}$ & Frequency & $\%$ \\
\hline Didactic lecture & 15 & 12.6 \\
\hline Tutorial & 19 & 16.0 \\
\hline Group discussion & 54 & 45.4 \\
\hline Seminar & 15 & 12.6 \\
\hline Demonstration & 16 & 13.4 \\
\hline \multicolumn{3}{|c|}{ The ideal teaching learning media for learning } \\
\hline LCD projector & 15 & 12.6 \\
\hline Blackboard & 10 & 8.4 \\
\hline LCD projector + Blackboard & 94 & 79.0 \\
\hline The most difficult systemto understand from & \\
\hline Autonomic nervous system & 16 & 13.4 \\
\hline General pharmacology & 10 & 8.4 \\
\hline Cardiovascular system & 13 & 10.9 \\
\hline Endocrine & 14 & 11.8 \\
\hline Antimicrobials & 62 & 52.1 \\
\hline Drugs acting on gastrointestinal system & 4 & 3.4 \\
\hline Drug acting on CNS & 16 & 13.4 \\
\hline
\end{tabular}

Student's opinion about changes recommended in teaching pharmacology at NGMC

Most of the student neither want to increase number of lectures $(57.1 \%)$ nor wants to decrease the number of lectures $(76.5 \%)$. High proportion of students wanted the faculty members to make more use of Audio-Visual aids (93.3\%)) case based learning, 96.6\%, clinical pharmacology, $97.5 \%$ and group discussions, $88.2 \%$ to be introduced in the curriculum for effective learning (Table 4).

\section{DISCUSSION}

Student feedback has been considered to be an effective methodology for modification of undergraduate curriculum and making pharmacology more interesting and practicable. Student feedback is thus considered an invaluable tool for improving students performances when suggestions obtained from students are implemented. ${ }^{9}$ In general, the majority of students who participated in this research expressed a positive perception of the teaching 
and learning of pharmacology. The percentage average of agreed responses for fifteen questions $(58.92 \pm 19.53)$ was significant $(\mathrm{p}<0.05)$ when compared with the percentage average of the disagreed (5.42 \pm 5.17$)$.

Table 4: Students' opinion about changes recommended in teaching pharmacology at NGMC $(\mathbf{n}=119)$.

\begin{tabular}{|lll|}
\hline Statements & Yes & No \\
\hline $\begin{array}{l}\text { Increase the number of } \\
\text { lectures }\end{array}$ & $51(42.9 \%)$ & $68(57.1 \%)$ \\
\hline $\begin{array}{l}\text { Make more use of audio- } \\
\text { visual aids }\end{array}$ & $111(93.3 \%)$ & $8(6.7 \%)$ \\
\hline Introduce student seminars & $101(84.9 \%)$ & $18(15.1 \%)$ \\
\hline $\begin{array}{l}\text { Introduce Case Based } \\
\text { Learning (CBL) }\end{array}$ & $115(96.6 \%)$ & $4(3.4 \%)$ \\
\hline $\begin{array}{l}\text { Introduce more clinical } \\
\text { pharmacology }\end{array}$ & $116(97.5 \%)$ & $3(2.5 \%)$ \\
\hline $\begin{array}{l}\text { Decrease the number of } \\
\text { lectures }\end{array}$ & $28(23.5 \%)$ & $91(76.5 \%)$ \\
\hline $\begin{array}{l}\text { Introduce group } \\
\text { discussions }\end{array}$ & $105(88.2 \%)$ & $14(11.8 \%)$ \\
\hline
\end{tabular}

In this study, Seventy three $(61.3 \%)$ students agreed that pharmacology is a favourite subject but the preferences for pharmacology as a subject in post-graduation was low $18.5 \%$, which is similar with the study done by Mahfoudh A.M. et al. ${ }^{7}$ It is probably due to inadequate knowledge about this subject matter which is vital for booming careers in the clinical research and pharmaceutical industries and due to student's interests are biased toward clinical sciences rather than fundamental sciences with prospective earning far better than pharmacology careers. ${ }^{10,11}$

In our study, Majority of the students $82.4 \%$ prefer MCQs in the assessment, this is similar to finding by Jai Krishna et al61.4\%, Mahfoudh AM et al, 58.6\% and by Manjunath SM et al, 79.68\%.4,5,7 The reason might be due to MCQs are one of the major way of examination in different competitions like post-graduation selection, medical licensing examination, even though in passing university examination and also due to student somewhere uncomfortable facing long and short essay type questions, would prefer MCQs in their examinations.

In present study $96.3 \%$ students wanted to case base learning to be introduced in the curriculum which is similar with the study done of Manjunath SM et al, $98 \%$ and Jai Krishna et al, 73\%.4,5 High percentage (97.5\%) wanted to be introduced more clinical pharmacology. Similarly, (92.4\%) students agreed with pharmacology is more closely integrated with the clinical sciences and real cases from hospitals should be used during stimulated learning problems supported by studies from authors, $64.94 \%, 62 \%$ and $89.6 \% \% .^{4,5,7}$ Sixty five percent of students agreed for more integration of pharmacology during the clinical years was supported by the study of Manjunath SM et al, $73.43 \%$ and Rani V et al, which is believed to provide students with the opportunity to become acquainted with various diseases for this reason. ${ }^{4,12}$ That's why many medical schools have integrated pharmacology during clinical years and acquiring knowledge about drugs is essential for medical student to take the responsibilities for preventive, curative aspect of any clinical conditions in future. ${ }^{13}$

Majority of students $93.3 \%$ wanted the more use of AudioVisual aids for effective learning. Regarding, ideal teaching-learning media for pharmacology, it was the combination of LCD projector and blackboard (79\%) followed by LCD projector (12.6\%), was supported by the study of Manjunath SM et al, which was $81.25 \%$ and $18.75 \%$ respectively. ${ }^{4}$ students need of more clinical orientation to the Pharmacology teaching at undergraduate level to make the subject more understandable and interesting with modern advancing technology of teaching learning. About $88.2 \%$ students in our study and $82 \%$ student by Manjunath SM et al, were recommend of introducing group discussions as a teaching-learning method in pharmacology, as it impart knowledge among faculties and student with easy feedback and discussion. ${ }^{4}$

\section{CONCLUSION}

The study determined that in general, the perceptions of the majority of participants regarding teaching-learning pharmacology were positive. Introduction of integrated teaching, case based, and group based discussion with clinical pharmacology was favoured by majority of the students. Regular reviewing perception and feedback of the students regarding learning pharmacology help teachers to plan the curriculum and improve the teaching methodologies for undergraduate students.

\section{ACKNOWLEDGEMENTS}

Authors would like to thank second year MBBS students of 2016 batch of NGMC, Chisapani, for participating in this project.

\section{Funding: No funding sources Conflict of interest: None declared \\ Ethical approval: Not required}

\section{REFERENCES}

1. Sekhri K. Teaching methodologies in pharmacology: a survey of students' perceptions and experiences. J Educ Ethics Dent. 2012;2(1):40.

2. Padmanabha TS, Manu G, Gajanan P, Kulkarni, Chandrakantha T, Neha K. Second year medical student's feedback and perspective on teaching methodology in Pharmacology in a tertiary care teaching hospital from India. Sch. J. App. Med. Sci., June 2016;4(6C):2089-94. ISSN 2320-6691 (Online), ISSN 2347-954X (Print)

3. Bhosale UA, Yegnanarayan R, Yadav GE. Attitude, perception and feedback of second year medical students on teaching learning methodology and 
evaluation methods in pharmacology: a questionnairebased study. Niger Med J. 2013;54:33.

4. Manjunath SM, Nagesh Raju G, Srinivas TR, Somes wara GM. A study on the evaluation of medical students' perception and feedback of teachinglearning of pharmacology in a medical college. IAIM. 2015;2(9):102-10.

5. Jai K, Abhishek S, Shwetank G, Aakansha G, Priyamvada S, Mirza URB, et al. Students' current perceptions and feedback on teaching and learning Pharmacology from an evolving medical school. IAIM. 2015;2(7):99-104.

6. Lalit Mohan BC, Adiga S, Shenoy S, Bairy K, Kishore A. Undergraduate medical students' perceptions regarding personal drug selection exercise. IJPCS. 2012;1(2):61-7.

7. Mahfoudh AM, Abdulghani, Redhwan A, Al-Naggar. Students' perceptions about learning pharmacology at a single private institute in Malaysia. Journal of Taibah University Medical Sciences. 2015;10(1):40-4.

8. Zgheib NK, Simaan JA, Sabra R. Using team-based learning to teach pharmacology to second year medical students improves student performance. Medic Teach. 2010;32:130-5.

9. Badyal DK, Bala S, Kathuria P. Student evaluation of teaching and assessment methods in pharmacology. Indian J Pharmacol. 2010;42:87-9.
10. Debjit B, Margret C, Chiranjib B. Emerging trends of scope and opportunities clinical trials in India. International $\mathbf{J}$ of Pharmacy and Pharmaceutical Sciences. 2010;2(1).

11. Amberkar M, Mohan L, Kumari M, Bairy KL. A survey on methods of undergraduate pharmacology teaching. JPRHC. 2011;3(2):43-9.

12. Rani V, Tekulapally K, Padmavath IV, Simpson GB. Second year Medical students perception about pharmacology and teaching methodologies used: A questionnaire based cross sectional study. Indian Journal of Basic and Applied Medical Research. 2016;5(4):238-45.

13. Dunaway GA, Faingold CL. Development and implementation of a multidisciplinary sophomore medical curriculum: integration of pharmacology with basic and clinical sciences. Pharmacologist. 2001;43:83-90.

Cite this article as: Dhami DB, Rathor RS, Bhargava VK, Neupane G, Singh R, Singh A. Student's perceptions and feedback about teachinglearning pharmacology in Nepalgunj medical college of Chisapani, Nepal. Int J Basic Clin Pharmacol 2017;6:2789-93. 